\title{
Applicability of Process Maps for Simulation Modeling in Business Process Change Projects
}

\author{
Aleš Popovič, Mojca Indihar Štemberger, and Jurij Jaklič \\ University of Ljubljana, Ljubljana, Slovenia
}

\author{
ales.popovic@ef.uni-lj.si mojca.stemberger@ef.uni-lj.si \\ jurij.jaklic@ef.uni-lj.si
}

\begin{abstract}
There are several techniques and tools that attempt to effectively represent different modeling perspectives according to business process modeling purpose and goals. One of widely used techniques for process modeling is process maps. The technique is based on flowcharts and one of its most important advantages, that is extremely important in early phases of business process change projects, is that models are easily understandable to all members of a project group. It is believed that this technique can provide only basic facilities in representing processes and is inappropriate for simulation. The main objective of this paper is to show that process maps have all elements required for simulation and that they have some other benefits, very important for business process renovation, that are discussed in the paper.
\end{abstract}

Keywords: business process simulation modeling, modeling technique, process maps, business process change, business process renovation

\section{Introduction}

Today, a focus on business processes is still worth considering for several reasons: it helps us to see organizations from a holistic and dynamic perspective, it encourages organizations to focus on customers and it reveals the need for flexible and responsive delivery mechanisms so as to meet the changing customers' needs. Besides, a business process standpoint enables organizations to focus on the mechanisms required to get things done and on finding ways to improve them and, according to Garvin (1998), it introduces an intermediate level for analyzing organizations - business processes are the link that enables organizations to migrate from intention to action, from strategic vision to operational execution.

Business process modeling has emerged as an important research and application area within organizational and information system design. Business process models can be used to serve a wide number of applications, for example to drive a strategic organizational analysis, to improve the existing processes, to derive requirements and specifications for information systems design, or to

Material published as part of this journal, either on-line or in print, is copyrighted by the Informing Science Institute. Permission to make digital or paper copy of part or all of these works for personal or classroom use is granted without fee provided that the copies are not made or distributed for profit or commercial advantage AND that copies 1) bear this notice in full and 2) give the full citation on the first page. It is permissible to abstract these works so long as credit is given. To copy in all other cases or to republish or to post on a server or to redistribute to lists requires specific permission and payment of a fee. Contact Publisher@InformingScience.org to request redistribution permission. support (semi)automated execution of processes or so called workflows (Costa \& da Cunha, 2006; Paul, Giaglis, \& Hlupic, 1999). Curtis, Kellner, and Over (1992) had identified several modeling goals and objectives: facilitate human under-standing and communication, support process improvement, support process management, auto-mated guidance in performing process and auto- 
mated execution support. Rosemann (1996) further found process modeling to be effective in supporting knowledge management, human re-source management and project management.

The focus of this paper is on process modeling with the purpose of business process renovation, where the main objectives are to support human understanding and communication and to support process improvement. Business process renovation (BPR) could be recognized as a form of continuous organizational change in which companies change and improve their business models, strategies and goals (Trkman \& Groznik, 2006). It integrates a radical strategic method of business process reengineering and a more progressive method of continuous process improvement with adequate information technology (IT) and e-business infrastructure strategies. Models of business processes play an important role in different phases of a BPR project regardless of the methodology used (Desel \& Erwin, 2000, Prasad, 1999).

The need to deal with business processes has caused an increased need for suitable modeling techniques and tools for their identification, modeling and analysis that result in a rapidly growing number of such techniques and tools (Trkman, Indihar Stemberger, \& Jaklic, 2005). Kettinger, Teng, and Guha, (1997) report about at least 72 techniques and 102 tools, while Hommes' (2001) survey revealed approximately 350 business process modeling tools. No single technique or approach can capture the whole spectrum of requirements posed by different people and applications. The choice of a modeling technique for a particular project should be based on matching the virtues and limitations of various techniques with the objectives of the project (Srinivasan \& Jayaraman, 1997, Paul et al., 1999). Giaglis (2001) proposed an evaluation framework and taxonomy of modeling techniques.

There are several techniques and tools that attempt to effectively represent different modeling perspectives and fulfill various goals and objectives. As already observed in Curtis et al. (1992) such modeling techniques may generate complex models and reduce the ease of use for any single particular application. On the basis of our involvement in some BPR projects we came to a conclusion that complex models are a big obstacle especially in early phases of such projects when the focus is on human understanding and communication.

On the other hand, processes need to be analyzed and different scenarios have to be evaluated to support their improvement. The methods of business process change (BPC), which combine business process modeling with the analysis of process performance, are one of the possible approaches that can be used for the analysis of the existing processes and for the evaluation of redesigned processes. Simulation can provide a valuable mechanism for addressing the problem of quantitative and qualitative evaluation of business processes. It can facilitate experimentation with and study of multiple perspectives of organizations, thus contributing toward increasing the quality of change decisions.

One of widely used techniques for process modeling is process maps. The models made by this technique are easily understandable to people without a special modeling knowledge and thus contribute to easy communication among the members of a BPR project group. It is believed that this technique can provide only basic facilities in representing processes and is inappropriate for simulation. The main objective of this paper is to show that process maps have all elements required for simulation and that they have some other very important benefits, if the modeling objectives are to support human understanding and communication and to support process improvement.

The paper is structured as follows: in the next section simulation modeling of business processes is discussed. Then process maps modeling techniques are described. Process maps appropriateness for simulation modeling in BPR projects is analyzed in section 4. Conclusion remarks and some further research directions are the content of the last section. 


\section{Business Process Simulation Modeling}

Several definitions of business processes can be found in literature but, as observed by Giaglis et al. (1999), all of them have something in common. Most authors agree that processes have internal or external customers and have to produce an output for them. Business processes are decomposed into a number of more elementary steps (activities) that are executed according to certain rules. During their execution, activities have to be coordinated (Desel \& Erwin, 2000). Resources have to be provided where needed for the execution of activities. A process has to be described in a way specifying which activities have to be executed in what order and what resources are needed for the execution of these activities.

\section{Role of Simulation in BPR Projects}

Business process modeling and the evaluation of different alternative scenarios for improvement are usually the driving factors of a business renovation process (Bosilj-Vuksic, Indihar Stemberger, Jaklic, \& Kovacic, 2003). Techniques and tools that enable modeling business processes, evaluation of their performance, experimenting with alternative configurations and process layouts, and comparing between diverse proposals for change, are highly suitable for organizational design. Simulation of business processes creates an added value in understanding, analyzing, and designing processes by introducing dynamic aspects. It enables migration from a static towards a dynamic process model (Aguilar, Rautert, \& Alexander, 1999). Computer based simulation models of business processes can help overcome the inherent complexities of studying and analyzing organizations and therefore contribute to a higher level of understanding and designing organizational structures (Giaglis et al., 1999).

Simulation is generally defined as a set of numerical and programming techniques for representing stochastic models and conducting sampling experiments on those models using a digital computer (Seila, Ceric, \& Tadikamalla, 2003). It is a set of techniques belonging to analysis methodology that involves methods for extracting information from a model by "observing" its behavior with the use of a digital computer. A simulation model is a model that has been adapted to be analyzed by means of simulation.

There are some modeling requirements specific to simulation-assisted business renovation modeling (Giaglis \& Paul, 1996):

- Processes need to be formally modeled and documented.

- Modeling should take stochastic nature of business processes into account, especially the way in which they are triggered by external factors.

- There is a need to quantitatively evaluate the value of proposed alternatives.

- The evaluation is highly dependent on the objectives of the particular study.

- Modeling tools should be easy to use to allow users of the processes to be involved in the modeling process.

Thus, simulation is a technique that uses a model to make predictions about a system or process (Harmon, 2003). There are different types of simulation, some more informal and some more formal. The technique that is the most suitable for simulation of business processes and is also implemented in the majority of simulation software is the discrete-event simulation - DES (Seila et al., 2003). Discrete simulations allow system quantities to change only at discrete points in time that are called events (for example arrival of a new customer). Computer-based discrete-event simulation relates to a symbolic representation of processes in ways that can be made persistent, replayed, dynamically analyzed, and reconfigured into alternative scenarios (Paul et al., 1999). 
Simulation can serve as a tool for deriving new knowledge on current business processes, such as additional in-depth understanding of how the process is executed and the identification of the sources of the problems observed during the process execution (Bosilj-Vuksic et al., 2003). Simulation offers a wide range of possibilities for analyzing time/cost/resources aspect of a business process and can aid business decision makers in prioritizing improvement actions and resource allocation decisions.

A first phase of a BPR project usually consists of identifying, describing and mapping (modeling) the processes of an organization. The results have to be communicated carefully so that everybody in the company understands the concept of process orientation and the mapping results. By introducing dynamic parameters of the process, like times, volumes, capacities and costs, simulation fundamentally enhances process performance analysis. It provides a much better picture of bottlenecks, hand-over times and dynamic performance than a static analysis. In order to detect weak points and opportunities for improvement, process performance is evaluated and benchmarked (Aguilar, Rautert, \& Alexander, 1999).

The main purpose of simulation is directed towards performance analysis and design of future processes as illustrated in Figure 1 (Aguilar, Rautert, \& Alexander, 1999). With a help of process simulation tools values are assigned to the activities and then a number of executions is performed to see how the business process will respond (Harmon, 2003). Thus, simulation has also an important role in analyzing the activities before changes are introduced, since it enables quantitative estimations to be made on the influence of the redesigned process on system performances (Bhaskar et al., 1994). Any envisaged change in process design can be anticipated and evaluated by simulation. The experimentation results can significantly contribute to the decisions about future process design.

Greasley \& Barlow (1998) also identified several areas in BPR projects where simulation modeling can be useful: identification of processes for change, identification of change possibilities, definition of process vision, understanding of current processes, and design and prototyping of new processes.

Simulation further supports the communication and implementation steps illustrated by the light grey areas in Figure 1. Modeling and simulation of entire process helps all participants to adapt a

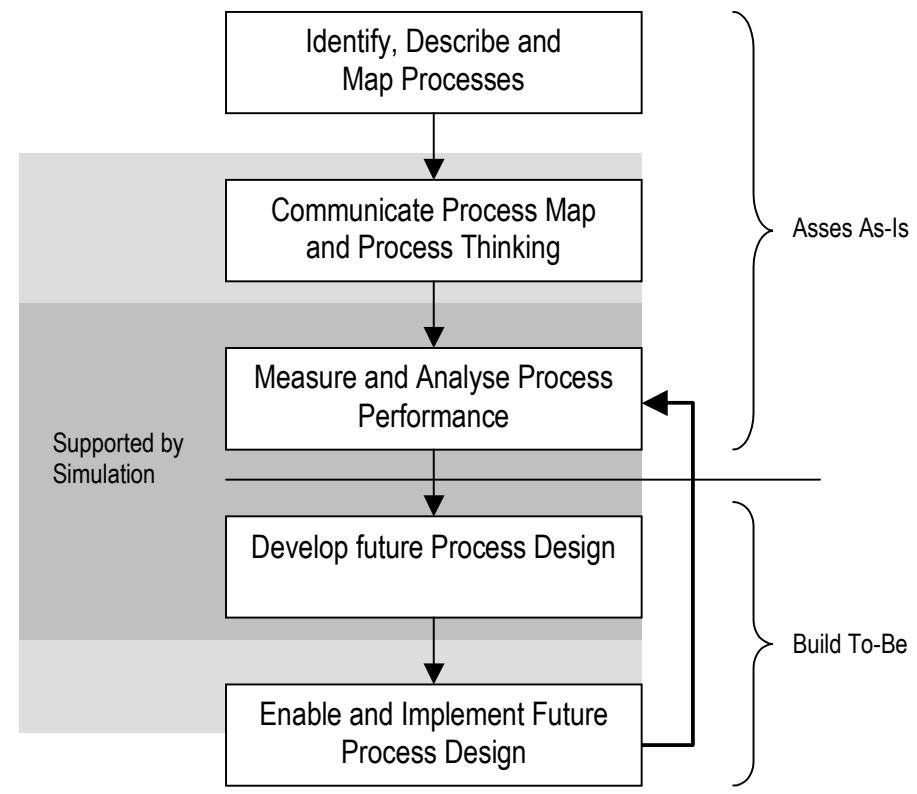

Figure 1: The main impact of simulation in BPC (Aguilar \& Rautert, 1999). 
Popovič, Indihar Štemberger, Jaklič

process perspective, to understand their contribution to the process result and to reflect about the interactions with others in the process. Therefore simulation facilitates communication and redirects people to the most important objective: improving process performance (Aguilar, Rautert, \& Alexander, 1999).

Thus, simulation of business processes has many benefits for BPR projects. Besides simulation usefulness and tools availability there are still many open issues when modeling business or "human-based" systems around to which practitioners and researchers have been devoting their attention. Among these issues there are data collection issues (many data have to be collected for running simulation, which is sometimes very time demanding), hierarchical decomposition modeling issues and granularity issues (the level of details has to be balanced with project goals) (Levas, Jain, Boyd, \& Tulskie, 1995; Popovic \& Jaklic, 2004). Others include the difficulty of modeling situations where a large amount of discretion is available in how tasks are undertaken and the difficulty of using simulation for prediction when the method of carrying out tasks evolves over time. Some of these issues are discussed in the following sections and can be overcome by a suitable process modeling technique and tool selection.

Many process improvement methodologies consider also only single processes and allow improvements to that process, but do not consider the effect of the changes on other processes within the business. It may be that improvements to the studied process may have a detrimental impact on the business as a whole. To be absolutely sure that process improvements benefit the business, then the entire business should be modeled and evaluated. However, it is very difficult (if not impossible), expensive and time consuming to simulate a model compounded of many interacting complex processes. Barber, Dewhurst, Burns, and Rogers, (2003) therefore suggest developing a limited simulation model for chosen segments of business processes.

\section{Techniques and tools}

For the implementation of simulation, computer tools are necessary. Every tool is based on some technique that has to include all the required elements for the simulation. Since DES simulation is suitable for the simulation modeling of business processes, the tool and the underlying technique has to enable all the elements necessary for this type of simulation. The elements required for DES simulation are described in next section, where the suitability of process maps for simulation modeling of business processes is discussed.

Over the past years, several software tools have been developed specifically for modeling business processes and their simulation. With most of these tools models are built from graphical symbols. Special characteristics of each process or activity may then be attached as attributes of the process. Many of these tools also allow for some type of activity-based costing or simulation analysis depending on the sophistication of the underlying modeling technique.

Most simulations studies are reported in the industrial sector, with limited successes reporting from other (non-manufacturing) sectors. A successful deployment of BPS tools in a limited BPR exercise in the telecommunications industry was reported in Lee and Elcan (1996) and a similar successful study in assessing the value of e-commerce is reported in Giaglis, Paul, and Doukidis (1998). When choosing simulation software for DES in BPC projects it is important to identify the project objective, since a common understanding of the objective will help frame discussions with internal company resources a well as vendors and service providers. Other important questions deal with model dissemination across the organization for others to use, model builders and model users, type of process (assembly lines, counter operations, material handling) the models will be focused, range of systems represented by the models, the approved budget, the flexibility of soft-ware vendor (license fees, upgrade fees, and technical support) and so on. 
Since the focus of this paper is on modeling to support human understanding and communication and to support process improvement, it is very important that models are understandable and that tools are easy to use. Visual interactive simulation (VIS) meets this request. The basic features of VIS can be summarized as the ability to build and modify simulation models on-screen, execute graphic simulation models, animate models as they execute, present simulation output graphically, and interact with the model during execution (Seila et al., 2003). It can contribute to communication of process thinking and to the acceptance of simulation results.

At this point it is reasonable to address the question of how business process simulation tools differ from other simulation tools such as manufacturing simulators. This does not mean, though, that general-purpose simulators are unable to model business processes, but this may be at the cost of additional programming. The differences become evident, when tools from different backgrounds are compared because they were possibly designed to fit different purposes. The multifaceted modeling approach of the IS modeling based tools seems more suited to model (semi)automated processes and/or to support the design of an information system. The tools with a manufacturing background, on the other hand, generally offer better business process abstractions than the IS ones and, thus seem to be more appropriate for business process simulation modeling.

Finally, it is also important to realize that business process simulation modeling tools are not without limitations. Mostly they are simple VIS tools specifically designed for business use and for producing fast results without requiring elaborate coding. Although such tools are invaluable for a coarse-grained, quick modeling exercise, they are unable to cope with complex, detailed simulations because they are usually devoid of a systematic mechanism to extend the pre-built logic. Last, but not least, process simulation is only a simple representation of reality and as such can not represent all aspects of business processes.

\section{Process Maps}

Processes can be modeled with different, mostly graphical, techniques - one of the more popular is process maps. Process maps are a proven analytical, communication and management tool intended to help process participants understand real business processes, make improvements to them or to implement a new process-driven structure in order to renovate business processes (Hunt, 1998). They were initially developed and implemented by General Electric as part of their integrated strategy to significantly improve their bottom-line business performance (Boehringer, 2003).

Process maps are based on flowcharts that are one of the first graphical modeling techniques. Nowadays flowcharts are very useful as a simple, graphic means of communication, intended to support understandable descriptions of processes (Giaglis, 2001). By reviewing articles in the fields of business process renovation and business process management a set of standard flowchart symbols most commonly used to model business processes can be identified (see Symbols 1 to 3 in Table 1). Some advanced flowcharts might show some of the inputs, but rarely take into account all of the process information.

Process maps, on the other hand, provide additional process information opposite to simple flowcharts (van Ackere, Larsen, \& Morecroft, 1993). Process maps consider information as time, resources (personnel, material and equipment), environment (functions or departments), outputs, etc. For each step in the flowchart we add the information and thus have a real understanding of the process. Each graphic symbol (see Table 1) can be additionally described in a structured text format and for the purpose of simulation tools usually enable associating these information to graphic symbols. Association of information to graphic symbols is usually not seen on the model graphic. 
Table 1: BPM symbols.

\begin{tabular}{|c|c|c|c|}
\hline & Symbol & Indicates & Examples \\
\hline 1 & & Start / finish & $\begin{array}{l}\text { Receive sales report } \\
\text { Customer arrives }\end{array}$ \\
\hline 2 & & Activity & $\begin{array}{l}\text { Check merchandise } \\
\text { Prepare customer invoice }\end{array}$ \\
\hline 3 & & Decision point & $\begin{array}{c}\text { Approve / Disapprove } \\
\text { Accept / Reject }\end{array}$ \\
\hline 4 & & Delay & Waiting for customer's response \\
\hline 5 & & Sub process & Ship merchandise \\
\hline 6 & & Organizational unit & $\begin{array}{l}\text { Sales department } \\
\text { Marketing }\end{array}$ \\
\hline 7 & & Process flow & \\
\hline
\end{tabular}

The authors of this paper understand process maps as a technique for graphic representation of logical steps in a process by considering activities (including duration, resources, constraints and costs), decision points, resources (types, number and costs), process delays, hierarchical decomposition (sub-processes) and organizational structure (e.g. departments). Modeling elements (symbols) are connected with links that describe the process flow and activities are placed in one or more departments (e.g. organizational units performing these activities). A process can be broken down into sub-processes to get a more detailed view (the level of detail is defined by the goal of the modeling). Delays are clearly noted in order to ease fast spotting of potential "bottleneck" areas in the process.

Figure 2 shows an example of using the process map technique, the model of a process that was previously presented in (Jaklic, Groznik, \& Kovacic, 2003). The figure also shows sample details collected for an activity.

Advances in software technology support integration of technologies such as process mapping and simulation that previously functioned only as stand-alone applications (Giaglis \& Paul, 1996). The fact is that today many of the more powerful business process tools offer simulation. While a certain amount of expertise is required to build models with most simulation languages, process modeling tools that apply process maps as a modeling technique usually offer a possibility for an easy to use VIS simulation. 


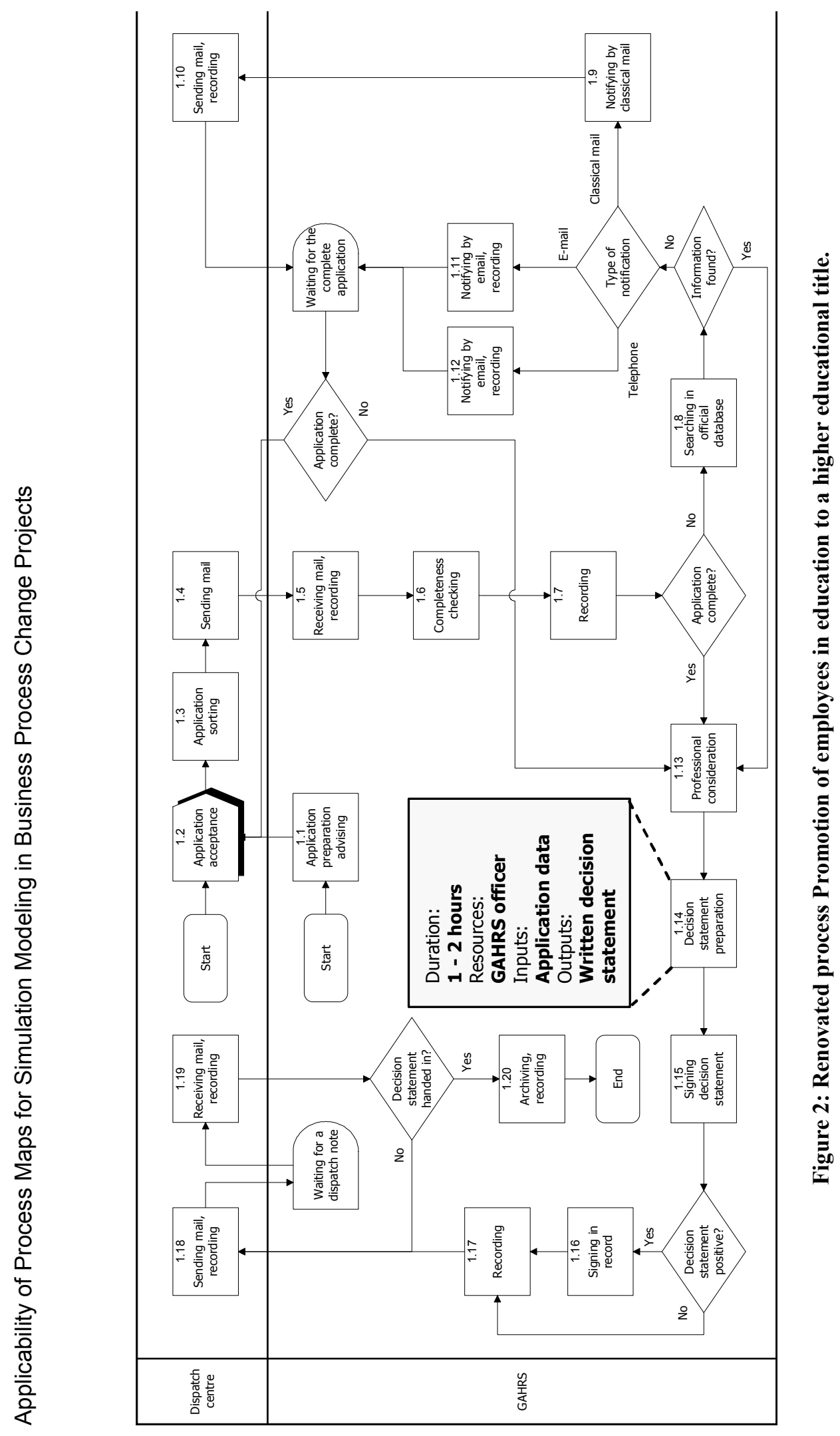

$\stackrel{\circ}{ }$ 


\section{Process Maps in Simulation: Suitable?}

As discussed before, business process modeling has several modeling goals and objectives that result in different requirements for modeling techniques. Curtis et al. (1992) proposed five different goals and objectives presented in Figure 3.

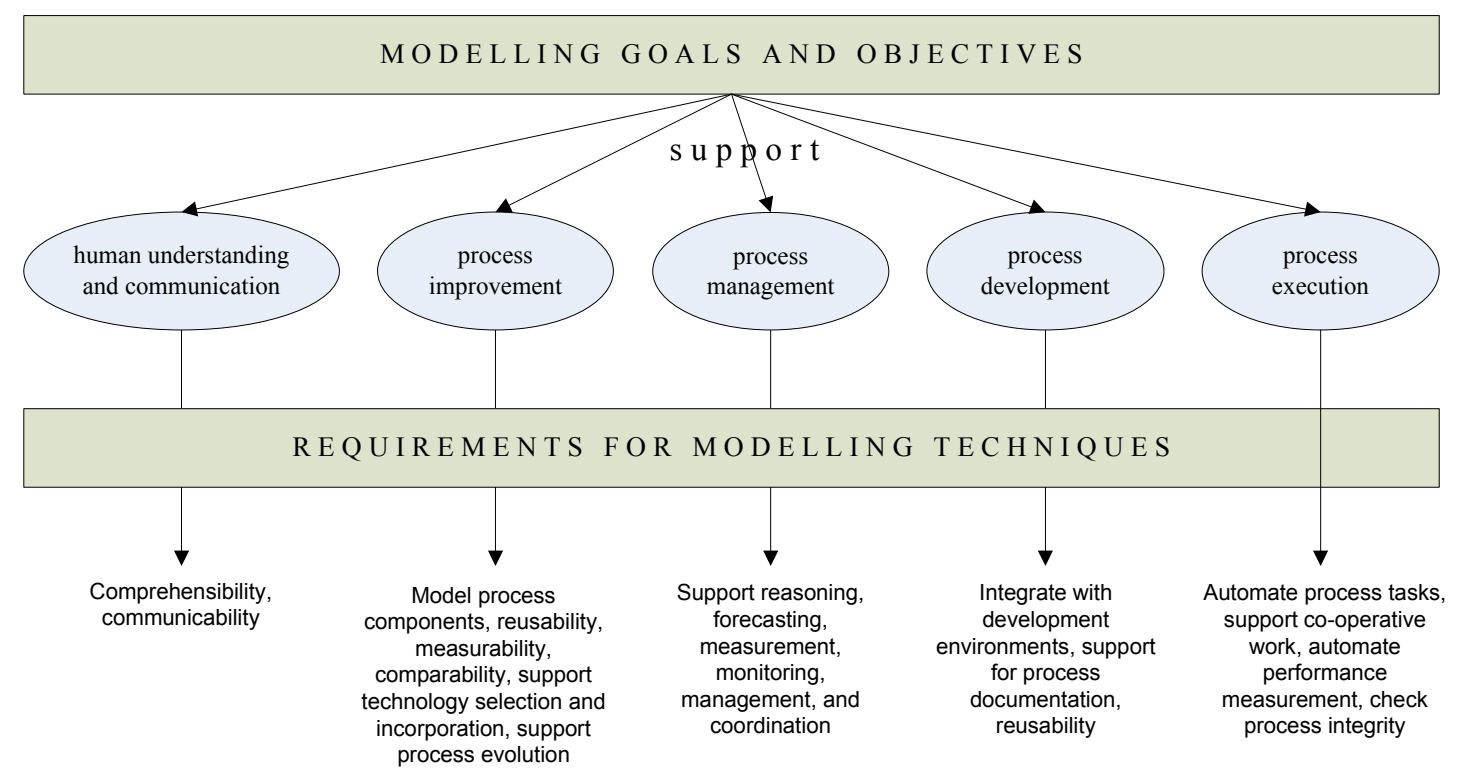

Figure 3: Goals and objectives of business process modeling (Curtis et al., 1992; Giaglis, 2001).

In BPR projects process modeling mostly addresses the first two goals, i.e. support human understanding and communication and support process improvement. Overlooking communication is identified as one of four most damaging practices in reengineering work (Bhaskar et al., 1994). Therefore the first requirement or criteria for selecting a technique in a BPR project would be clarity for the intended users.

In Guidelines of Modeling, Becker, Rosemann, and von Uthmann (2000) stressed six principles that are important for business process modeling: correctness, relevance, economic efficiency, clarity, comparability, and systematic design. The guideline of clarity is extremely subjective and postulates that the model is understood by the model user. Clarity of models is especially important when the objective of business process modeling is to facilitate human understanding and communication or to support process improvement. Although several different graphic notations are used to present process maps, it has to be observed that in the analysis and design phase it is important to use a notation that is easily understandable to the process participants. The actual notation used is of secondary importance; it is more important that the process team feels comfortable (Kawalek \& Kueng, 1997).

As suggested by Harmon (2003), many different groups are involved in business process modeling. Predictably, different groups use different types of diagrams. The key thing to think about in selecting any notation is who is going to use it. As the main target audience of the process models in BPR projects are people who perform activities in processes and other members of BPR team it is clear that the elements of the process models that are only used to describe software conventions should be omitted. Without a readable, understandable, useful model all other efforts become obsolete. 
To accommodate the objectives and goals of BPR, a model must be capable of providing various elements to its users. Such elements include, for example, what activities constitute the process, who performs these activities, when and where the activities are performed, how and why they are executed, and what data elements they manipulate (Giaglis, 2001). For the business process analysis in BPR projects the data about who performs activities, other required resources, duration etc. are important regardless of the fact whether simulation is going to be used as an analysis technique or not.

\section{Evaluation of Process Maps Technique}

The process maps technique enables modeling of business processes in a way that is as easy to understand as possible, while it is still possible to describe (Harmon, 2003) all of the basics that need to be described for the intended purpose, i.e. process analysis for BPR and communication. Process maps can be very effective communication tools that in a very simple visual format facilitate - across internal and external organizational boundaries - transmission of ideas concerning what is actually happening in business and ways to improve the business.

Bhaskar et al. (1994) proposed a set of requirements that should be met by tools used for modeling and simulation of business processes. These requirements can be divided into five groups: process documentation, process redesign, performance measurement, communication, and institutional learning. Based on our analysis and our experience from BPR case studies we think that process maps based tools meet these requirements.

Hommes \& van Reijswoud (2000) have developed a framework for the evaluation of business process modeling techniques. They propose eight evaluation criteria, which can be divided into two groups: one related to the conceptual modeling in general and another group related to the business process modeling in particular. They refer to the quality of the way of modeling and the way of working of a modeling technique respectively. These criteria are:

- Expressiveness - the degree to which a given modeling technique is capable of denoting the models of any number and kinds of application domains;

- Arbitrariness - the degree of freedom one has when modeling one and the same domain;

- Suitability - the degree to which a given modeling technique is specifically tailored for a specific kind of application domain.

- Comprehensibility - the ease with which the way of working and way of modeling are understood by the participants;

- Coherence - the degree to which the individual sub-models of a way of modeling constitute a whole;

- Completeness - the degree to which all necessary concepts of the application domain are represented in the way of modeling;

- Efficiency - the degree to which the modeling process utilizes resources such as time and people;

- Effectiveness - the degree to which the modeling process achieves its goal.

It has to be observed that the properties are not orthogonal. For example, van der Aalst (1993) suggests that the complexity and detail are essential to sound analysis; however excessive complexity and detail can impede human understanding of the process.

Using theoretical findings from the reviewed literature and our own experience we have evaluated the process maps technique based on these criteria. Additionally, for each criterion/property 
we have to evaluate the importance for the purpose of modeling, which is in our case business process renovation. As seen from the table 2, our estimation is that the process maps technique performs well for the criteria that are of high importance for the BPR projects.

Levas et al. (1995) discuss some of business process modeling issues (such as problem definition, data collection, socio-political issues, hierarchical and modular modeling, granularity, integration, and multi-perspective issues) needing attention in BPR projects. Another important issue in process modeling and simulation is the support for hierarchical decomposition and design modularity (MacArthur, Crosslin, \& Warren, 1994), which is also enabled by the process maps technique.

We found this technique very suitable for solving socio-political issues (by enhancing communication and understanding in a project group), hierarchical issues (by providing hierarchical (de)composition features), and granularity issues (by easily allowing modeling at different levels of details).

Table 2: Evaluation of the process maps technique.

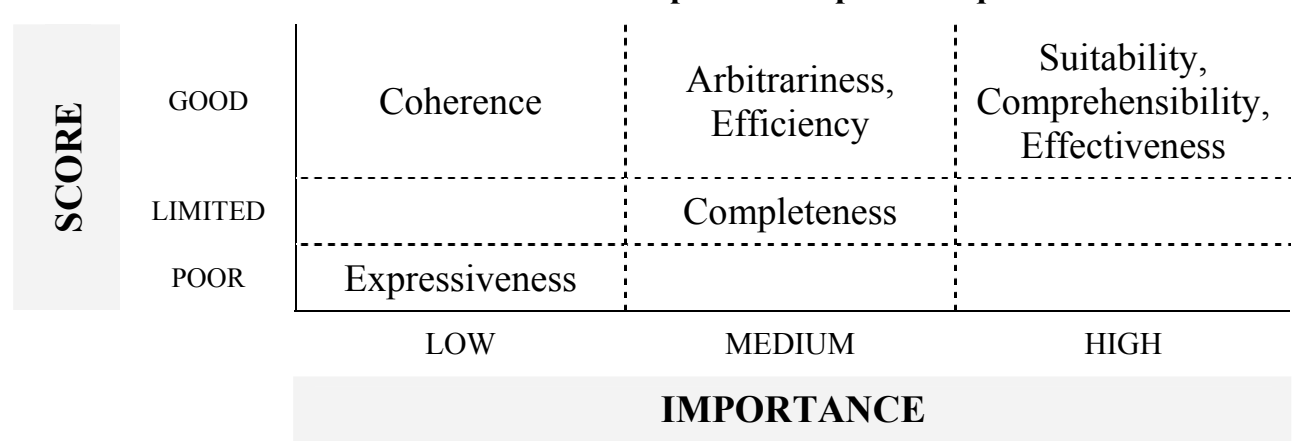

Van Ackere et al. (1993) argue that simple process maps do not typically provide sufficient understanding of the process to know what to change. Van der Aalst (1992) suggests that the intended analysis dictates the type of modeling that is done. The goals of a renovation effort are most often related to business improvement measures. The process maps help to understand the problem, but to help in knowing what to change, the process map must be supplemented by a quantitative analysis that is usually performed by using simulation.

\section{Suitability for Simulation}

As follows from the work of Curtis et al. (1992), the second criteria for selecting a modeling technique for BPR projects is the possibility to model process components, measurability, compare different scenarios etc. The static model description models the components that make up the system, but it does not tell how they interact (Seila et al., 2003). A complete model description must also include the system dynamics. The dynamic model description provides a set of rules telling how the components interact as time advances.

The process view represents system dynamics by joining a sequence of events and activities to follow the progress of a temporary entity through the system. A process consists of a routine that describes the sequence of related events (where the system state changes) and activities (the interaction between different entities over a specific length of time) for the entity - permanent or temporary (Seila et al., 2003). Giaglis et al. (1999) define process from the simulation point of view as a time-ordered sequence of interrelated events (activities) which describes the entire experience of an entity as it flows through a system.

Harrel \& Field (1996) argue that much of the process definition used in a simulation model is contained in a process map, yet insufficient data are provided in a process map for running simulation. Therefore additional information has to be manually added on the simulation side. Giaglis 
et al. (1999) state that several attempts of integrating process mapping and simulation have been made, although with not very successful results. In their opinion this is due largely to incompatibilities in both purpose and paradigm.

Our experience on BPR projects shows that for a detailed analysis of existing business processes, required by process renovation, more elements of the process model than just activities and process flow are required. A complete viewpoint may be difficult to establish using only fixed-process map descriptions. They address aspects of processes for which static activity and data modeling are inadequately suited, because they cannot cope with the impact of resource flow. Resources (permanent entities) and their costs, organizational structure, duration of activities and waiting times, events and their frequency are the necessary elements of a carefully prepared process model for a process (organizational) analysis. Process maps provide detailed information about observed processes, usually presented on separate sheets (see Figure 2) that are filled in as the process map is developed. This leads to the conclusion that a properly designed process map model contains all the necessary information for a DES analysis of a business process.

The only element of simulation that is not fully supported by process maps is an explicit definition (presentation) of events. In certain other, more structured modeling techniques, such as eEPC (extended Event-Driven process Chain) each activity is triggered by an event and the result of each activity is an event. With process maps this is not a case, however we do not consider this as a weak point of the process maps technique considering the purpose of modeling in our case, i.e. process analysis and renovation which requires a great deal of communication and therefore comprehensibility. Also, from the formal point of view an activity consists of a starting event followed by an ending event that is scheduled by the staring even (Seila et al., 2003), which implies that it is not necessary to model events separately. We found more formal technique regarding modeling of events as less understandable.

\section{Conclusion}

Simulation modeling has many benefits for BPR projects for analyzing the existing processes and evaluation for alternative scenarios of their improvement. In the paper we have analyzed suitability of the process maps technique for simulation based process analysis.

From the literature review and our own research work (Bosilj-Vuksic et al., 2003; Indihar Stemberger, Jaklic, \& Popovic, 2004; Jaklic et al., 2003) we can conclude that flowcharts do not have all the re-quired elements for simulation modeling (e.g. duration of activities, waiting times, costs) (Giaglis, 2001). However, process maps as defined in the paper have all modeling elements formally required for simulation. With additional benefits, such as clarity of models, this technique and the tools based on it can be very efficient for the first two modeling goals according to (Curtis et al., 1992) that are related to BPR projects.

Process models built by using process maps technique can serve as a base for identifying information requirements and planning of information system development projects. They are also very suitable for the introduction of a workflow management system. Therefore, process maps can serve as a foundation for IS modeling. However, a single technique cannot capture all different aspects of modeling without becoming too complex and as a consequence less useful for early phases of BPR where communication of models is very important. 
Popovič, Indihar Štemberger, Jaklič

\section{References}

Aguilar, M., Rautert, T., \& Alexander, P. (1999). Business process simulation: A fundamental step supporting process centered management. Proceedings of 1999 Winter Simulation Conference, Phoenix, Arizona, 1383-1392.

Barber, K.D., Dewhurst, F.W., Burns, R.L.D.H., \& Rogers, J.B.B. (2003). Business-process modelling and simulation for manufacturing management: A practical way forward. Business Process Management Journal, 9 (4), 527-542.

Becker, J., Rosemann, M., \& von Uthmann, C. (2000). Guidelines of business process modeling. In W. van der Aalst, J. Desel, \& A. Oberweis (Eds.), Business Process Management Models, Techniques, and Empirical Studies (pp. 30-49). Berlin: Springer Verlag.

Bhaskar, R., Lee, H.S., Levas, A., Petrakian, R., Tsai, F., \& Tulskie, B. (1994). Analyzing and reengineering business processes using simulation. Proceedings of the 1994 Winter Simulation Conference, Lake Buena Vista, Florida, 1206-1213.

Boehringer, B. (2003). Process mapping: How to streamline and reengineer business processes. Outline of seminar on Process Management, Charlottesville, VA.

Bosilj-Vuksic, V., Indihar Stemberger, M., Jaklic J., \& Kovacic, A. (2003). Assessment of e-business transformation using simulation modelling. Simulation, 12, 731-744.

Costa, C.C., \& da Cunha, P.R. (2006). Workflows without engines: Modeling for today's heterogeneous information systems. Issues in Informing Science and Information Technology, 3, 175-187. Available at http://informingscience.org/proceedings/InSITE2006/IISITCost189.pdf

Curtis, B., Kellner, M.I., \& Over, J. (1992). Process modeling. Communications of the ACM, 10, 75-90.

Desel, J. \& Ervin, T. (2000). Modeling, simulation and analysis of business processes. In W. van der Aalst, J. Desel, \& A. Oberweis (Eds.), Business Process Management Models, Techniques, and Empirical Studies (pp. 129-141). Berlin: Springer Verlag.

Garvin, D. A. (1998). The process of organisation and management. Sloan Management Review, 39, 33-50.

Giaglis, G.M. (2001). A taxonomy of business process modeling and information systems modeling techniques. International Journal of Flexible Manufacturing Systems, 13, 209-228.

Giaglis, G.M. \& Paul, R.J. (1996). It's time to engineer re-engineering: Investigating the potential of simulation modelling in business process redesign. In B. Scholz-Reiter \& E. Stickel (Eds.), Business Process Modelling (pp. 313-332). Berlin: Springer-Verlag.

Giaglis G.M., Paul, R.J., \& Doukidis, G.I. (1998). Dynamic modelling to assess the business value of electronic-commerce. Proceedings of the 11th International Electronic Commerce Conference, Vol. 1, June, 57-73.

Giaglis, G.M., Paul, R.J., \& Hlupic, V. (1999). Integrating simulation in organizational design studies. International Journal of Information Management, 19, 219-236.

Greasley A. \& Barlow, S. (1998). Using simulation modelling for BPR: resource allocation in a police custody process. International Journal of Operations \& Production Management, 18, 978-988.

Harmon, P. (2003). Business process change: A manager's guide to improving, redesigning and automating processes. San Francisco: Morgan Kaufmann Publishers.

Harrel, C.R. \& Field, K.C. (1996). Integrating process mapping and simulation. In Proceedings of the 1996 Winter Simulation Conference, Coronado, California, 1292-1296.

Hommes, B. \& van Reijswoud, V. (2000). Assessing the quality of business process modeling techniques. Proceedings of the 33rd Hawaii International Conference on System Sciences, Maui, Hawaii, 1-10.

Hommes, B. (2001). Overview of business process modelling tools. Retrieved July 1, 2006, from http://www.isa.its.tudelft.nl/ hommes/tools.html 
Hunt, D.V. (1998). Process mapping - How to reengineer your business processes. New York John Wiley \& Sons.

Indihar Stemberger, M., Jaklic J., \& Popovic A. (2004). Suitability of process maps for business process simulation in business process renovation projects. Proceedings of 16th European Simulation Symposium, Budapest, 197-205.

Jaklic, J., Groznik, A., \& Kovacic, A. (2003). Towards e-government - The role of simulation modelling. Proceedings of 15th European Simulation Symposium, (2003), Delft, The Netherlands, 257-262.

Kawalek, P. \& Kueng, P. (1997). The usefulness of process models: A lifecycle description of how process models are used in modern organisations. Proceedings of The Second CAiSE97/IFIP8.1 International Workshop on Evaluation of Modeling Methods in Systems Analysis and Design, (1997), Barcelona, Spain.

Kettinger, W.J., Teng, J.T.C., \& Guha, S. (1997). Business process change: A study of methodologies, techniques, and tools. MIS Quarterly, March, 55-80.

Lee Y., \& Elcan, A. (1996). Simulation modelling for process reengineering in the telecommunications industry. Interfaces, 22(6), 1-9.

Levas, A., Jain, P., Boyd, S., \& Tulskie, W. (1995). Panel discussion on the role of modeling and simulation in business process reengineering. Proceedings of the 1995 Winter Simulation Conference, Arlington, Virginia, 1341-1346.

MacArthur, P.J., Crosslin, R.L., \& Warren, J.R. (1994). A strategy for evaluating alternative information system designs for business process reengineering, International Journal of Information Management, 14, 237-251.

Paul, R.J., Giaglis, G.M. \& Hlupic, V. (1999). Simulation of business processes. The American Behavioral Scientist, 42, 1551-1576.

Popovic, A. \& Jaklic, J. (2004). Problematika simuliranja poslovnih procesov. (Business process simulation issues) Management in informatika: Zbornik posvetovanja DSI 2004, 166-172.

Prasad, B. (1999). Hybrid re-engineering strategies for process improvement, Business Process Management Journal, 5, 178-197.

Rosemann, M. (1996). Complexity management in process models. Wiesaden, Germany: Gabler-Verlag.

Seila, A.F., Ceric, V., \& Tadikamalla, P. (2003). Applied simulation modeling. Southbank, Australia: Thomson Learning.

Srinivasan, K. \& Jayaraman, S. (1997). Integration of simulation with enterprise models. In Proceedings of 29 th conference on Winter Simulation, Atlanta, Georgia, 1352-1356.

Trkman, P., Indihar Stemberger, M., \& Jaklic, J. (2005). Information transfer in supply chain management. Issues in Informing Science and Information Technology, 2, 559-573. Available at http://2005papers.iisit.org/I46f91Trkm.pdf

Trkman, P. \& Groznik, A. (2006). Measurement of supply chain integration benefits. Interdisciplinary Journal of Information, Knowledge, and Management, 1, 37-45. Available at http://ijikm.org/Volume1/IJIKMv1p037-045Trkman22.pdf

van Ackere, A., Larsen, E.R., \& Morecroft, J.D.W. (1993). Systems thinking and business process redesign. The European Management Journal, 11, 412-423.

van der Aalst, W.M.P. (1992) Modelling and analysis of complex logistic systems. IFIP Transactions on Integration in Production Management Systems, Eindhoven University of Technology, Nether-lands, 277-292. 


\section{Biographies}

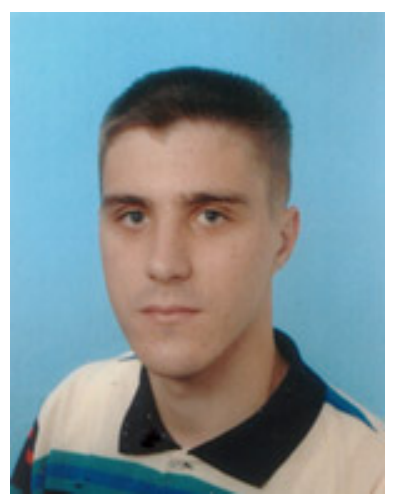

Aleš Popovič, M Sc., is an assistant lecturer for Information Management at Faculty of Economics, University of Ljubljana, Slovenia. His pedagogical work in the past five years was oriented mainly in preparing and performing computer workshops (lab lectures) for undergraduate business students. His main research interest is concentrated around the question of influence of contemporary Information Technologies and Information Management as a whole on (better) business performance. Topics of interest in view of that include business informatization, business process modeling, business process simulation, elearning, and education in the field.

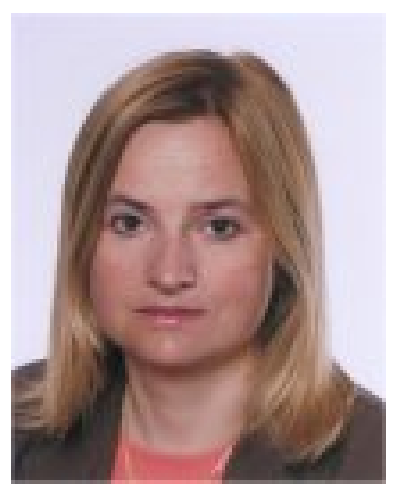

Mojca Indihar Štemberger received her Master in Computer and Information Science degree in 1996, and her Ph.D. in Information Science in 2000 from the University of Ljubljana, Slovenia. Currently she is an assistant professor at the Faculty of Economics, University of Ljubljana. Her research interests include business process renovation, e-business and decision support systems. She is a president of the Slovenian Informatics conference.

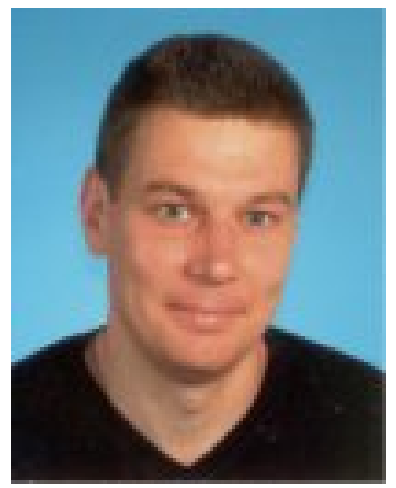

Jurij Jaklič received his Master Degree in Computer Science in 1992 from the University of Houston and his PhD in 1997 from the University of Ljubljana, Slovenia. Currently he is an associate professor at the Faculty of Economics, University of Ljubljana. His main research interests are business process reengineering, business renovation, ebusiness, decision support systems, and data and business modeling. $\mathrm{He}$ is a member of the program committee at the Slovenian Informatics conference. 